\title{
Relations Among Socioeconomic Status, Age, and Predictors of Phonological Awareness
}

\author{
Kimberly D. McDowell \\ Wichita State University, Wichita, KS \\ Christopher J. Lonigan \\ Howard Goldstein \\ Florida State University, Tallahassee
}

\begin{abstract}
Purpose: This study simultaneously examined predictors of phonological awareness within the framework of 2 theories: the phonological distinctness hypothesis and the lexical restructuring model. Additionally, age as a moderator of the relations between predictor variables and phonological awareness was examined.

Method: This cross-sectional quantitative study included a total of 700 participants between 2 and 5 years of age. Participants were identified as being from homes of lower or higher socioeconomic status (SES) based on preschool funding source, and they completed 2 measures of vocabulary, 8 measures of phonological awareness, and 2 measures of speech sound accuracy.

Results: Results indicate that SES, age, speech sound accuracy, and vocabulary each contributed unique variance to the prediction of phonological awareness. Age amplified the relations between speech sound accuracy and phonological awareness and between SES and phonological awareness but not between vocabulary and phonological awareness.

Conclusion: The current study provides further support for both the phonological distinctness hypothesis and the lexical restructuring model. Additionally, this study provides novel information regarding the role that age plays in the prediction models. Specifically, the effects of SES and speech sound accuracy on phonological awareness were amplified by age.
\end{abstract}

KEY WORDS: articulation, preschool, literacy, phonology, phonological awareness

$\mathrm{R}$ eading skills provide a vital foundation for children's academic success. Children who read well tend to read more and, as a result, acquire more knowledge in many content domains (Cunningham \& Stanovich, 1998). Although many children learn to read without significant problems, more than one in three experience considerable difficulty (Adams, 1990). Research shows a strong relationship between the skills of phonological processing, concepts of print, and oral language at school entry and later reading achievement (Baydar, Brooks-Gunn, \& Furstenberg, 1993; Shonkoff \& Phillips, 2000). Children who experience early reading difficulties receive less practice than other children (Allington, 1984), miss opportunities to develop reading comprehension strategies (Brown, Palinscar, \& Purcell, 1986), and may acquire negative attitudes toward reading (Oka \& Paris, 1986). This may lead to what Stanovich (1986) termed Matthew effects, whereby children with poor reading skills fall further behind their literate peers. Children with limited reading skills rarely catch up to their peers (Juel, 1988; Torgesen, Wagner, Rashotte, Alexander, \& Conway, 1997) and continue to experience difficulties throughout their academic careers. 
The causal relation between early reading success and phonological awareness has been well established (for reviews, see Adams, 1990; Catts \& Kamhi, 1999). Many studies have shown the importance of early sensitivity to the phonological structure of words, which is often referred to as phonological awareness (Blachman, 1991; Elbro, 1996). Children with low phonological awareness are at risk for developing reading difficulties (e.g., Elbro, 1996; Lonigan, 2003).

In addition to levels of phonological awareness, researchers have explored the impact of certain childlevel variables (e.g., age, socioeconomic status [SES], gender) on emergent literacy acquisition. This research provides researchers and practitioners alike with information that potentially helps to explain the nature of individual differences. For example, extant literature indicates that the development of phonological awareness is not a continuous function represented as a steady increase in ability across ages, but, rather, growth is accelerated in the older groups, which consisted of 4- and 5-year olds (Lonigan, Burgess, Anthony, \& Barker, 1998). Additionally, Foy and Mann (2001) reported that age was significantly related to phonemic awareness, rhyme awareness, naming speed, vocabulary, letter knowledge, and articulation ( $r \mathrm{~s}>.38$ ).

Extant literature also indicates that poverty is one of the strongest predictors of reading achievement (National Assessment of Educational Progress [NAEP], 2005). For the United States as a whole, $27 \%$ of fourthgrade students scored below the basic level on the NAEP assessment; however, for children falling below the poverty level, the percentage was $34.6 \%$ (NAEP, 2005). For some urban schools, the proportion of children falling below the basic level was as high as 68\% (Donahue, Voelld, Campbell, \& Mazzeo, 1998).

Finally, gender has been examined as a potential contributor to individual differences in reading-related skills. The scant literature available presents an inconsistent picture. Some studies indicate that gender differences in phonological awareness skills are apparent (e.g., Cormier \& Dea, 1997). In contrast, Hecht and Greenfield (2002) found that gender did not account for unique variance in teachers' ratings of students' reading achievement. Likewise, Burt, Holm, and Dodd (1999) found that girls and boys performed similarly on phonological awareness tasks. Finally, Elbro, Borstrom, and Petersen (1998) found that although more boys in their sample were later identified as having dyslexia, gender difference across families was not statistically significant.

In addition to these demographic variables, there is an additional set of potential predictor variables, stemming from distinct yet perhaps interwoven theories: the phonological deficit hypothesis and the lexical restructuring model. These variables may also help to explain individual differences in the development of phonological awareness and subsequent reading-related skills.

\section{Sublexical Versus Lexical Representations}

Phonological deficit hypothesis. The phonological deficit hypothesis posits that children with inefficient or weakly established phonological representations will have subsequent difficulties with phonological awareness tasks (e.g., Fowler, 1991; Shankweiler, Crain, Brady, \& Macaruso, 1992). More specifically, Elbro (1996) proposed that these weakly established representations are due to indistinct phonological representations. He proposed that differences in the distinctness of phonological representation of lexical items are a cause of many of the differences in phonological processing associated with difficulties in reading development. Distinctness is defined as the phonetic "difference between a lexical representation and its neighbors" (Elbro, 1996, p. 467). For example, in contrast to a complete representation of the word submarine, a less distinct representation would be subrine or sub (Elbro, Nielsen, \& Petersen, 1994). The distinctness hypothesis focuses on the phonetic detail of a word rather than the whole word. In the example then, sub is less distinct than submarine given that it is missing phonetic details. The distinctness of a lexical representation is a determinant of the completeness and accuracy of the representation, the ease of access to the representation, and access to sublexical phonological units within the representation.

The distinctness hypothesis purports that children with severe difficulties in making connections between graphemes and phonemes possess relatively indistinct phonological representations or have other difficulties accessing distinct phonological representations (Elbro, 1996). Thus, according to the distinctness hypothesis, deficits in phonological awareness could be directly attributed to deficits in the child's phonological system. If a child's underlying phonological system is less distinctly developed, one's ability to store, access, manipulate, and produce phonologically based information may be impaired.

There has been a limited amount of research in relation to the distinction of phonological representation hypothesis (e.g., Fowler \& Swainson, 2004; Swan \& Goswami, 1997). Most findings indicate that performance on phonological awareness tasks differs according to (a) accuracy and retrieval of the phonological representation and (b) the linguistic level tapped by the phonological awareness task.

Indirect support for the distinctness hypothesis is provided in the studies examining the relations among phonological awareness, reading, and speech sound accuracy. Studies examining these relations have indicated that children with speech sound inaccuracies performed 
more poorly on measures of word-level reading tasks (e.g., Larrivee \& Catts, 1999; Rvachew, Ohberb, Grawburg, \& Heyding, 2003) and that severity of speech sound inaccuracies played a role in predicting reading skills (e.g., Larrivee \& Catts, 1999; Nathan, Stackhouse, Goulandris, \& Snowling, 2004). Carroll, Snowling, Hulme, and Stevenson (2003) reported that receptive and expressive phonology skills were significantly correlated with measures of phonological awareness. Structural equation modeling was used to test the prediction that articulation would predict phoneme awareness approximately 12 months after initial assessment. Results indicated that articulation accounted for significant longitudinal influences on the development of phoneme awareness.

Lexical restructuring model. In contrast to the distinctness hypothesis is the lexical restructuring model (Metsala \& Walley, 1998), which has as its focus lexical (i.e., word-level) representations. As a child's lexicon grows in size and complexity, the child is faced with a need for a more specific, distinct phonological representation of spoken words so that access and retrieval are quick and accurate (Metsala, 1997; Storkel \& Morrisette, 2002). Metsala and Walley (1998) have proposed that this segmental representation is, in part, the product of the development of vocabulary. Their lexical restructuring model (LRM) was formulated to account for developmental changes in the structure of spoken word representations and the growth of phonological awareness. According to this model, the representations supporting spoken word recognition become increasingly segmental with spoken vocabulary growth, and this change makes possible explicit access to phonemic units. They proposed that lexical restructuring is a protracted process that extends into early and even middle childhood. This restructuring is influenced by the words that are known at a given point in time and that must be distinguished from one another for successful recognition. Variations across children in lexical growth and in the restructuring process contribute to individual differences in phonemic awareness and thus success in learning to read an alphabetic orthography.

Words in the lexicon can be thought of as being arranged based on lexical similarity (Luce \& Pisoni, 1998; Storkel, 2002). Words that are similar to only a few other words are said to be housed in sparse neighborhoods. In contrast, words that are phonologically similar to many words are said to be housed in dense neighborhoods. Storkel (2002) reported that in addition to type of neighborhood, words also vary in terms of type of similarity and place of overlap. Storkel (2002) found that for words in dense neighborhoods, representations are encoded based on similar phonemes in the onset + nucleus position of overlap or the rime position. In contrast, words from sparse neighborhoods are encoded by similar phonemes in the onset + nucleus position but by similarity of manner in the rime position. These findings support the lexical restructuring model in that words are initially represented by manner but are later represented by similar phoneme as lexical neighborhoods become more dense and increased segmentalization is required. Thus, according to the lexical restructuring model, deficits in phonological awareness could be directly attributed to deficits in the lexicon. If a child's vocabulary is less well developed, it may not be at a stage in which substantial lexical restructuring is necessary. If lexical restructuring has not occurred, adultlike phonetic features and segments may not be specified or may be specified indistinctly.

Additional studies support the notion of the lexical restructuring model (e.g., Metsala, 1999; Foy and Mann, 2001; Walley and Flege, 1999), with findings indicating that vocabulary knowledge was strongly related to phonological awareness skills. Additionally, Garlock, Walley, and Metsala (2001) found that vocabulary growth contributed to developmental changes in spoken word representation.

In summary, each theory predicts different influences of phonological (i.e., sublexical) and lexical skills on phonological awareness. The phonological deficit hypothesis predicts that speech accuracy should predict phonological awareness when vocabulary is controlled. The lexical restructuring model predicts that vocabulary should predict phonological awareness when speech accuracy is controlled. However, because the literature that suggests that the influences of vocabulary and phonological awareness may be bidirectional in nature (e.g., Storkel \& Morrisette, 2002), it could be that these two theories are not distinct but complimentary. Given the instructional and assessment implications that this bidirectionality would have, this possibility needs to be tested empirically.

\section{Age as a Moderator}

In addition to further exploring the relation between phonology and the lexicon, there are theoretical reasons to explore the possibility that some of the relations that have emerged in extant literature regarding variables that are related to phonological awareness and subsequent reading skills may be moderated by other variables. One such variable may be age. For example, evidence suggests that the relations among phonological awareness skills and speech sound accuracy skills change with age. Research conducted by McDowell, Lonigan, and Goldstein (2002) demonstrated that the relation between speech sound accuracy and phonological awareness changed over time (i.e., the relationship strengthened with age). Researchers who have examined the development of phonological awareness skills have also reported that as children increase in age, phonological awareness skills become more stable (e.g., Lonigan et al., 1998). Finally, use of developmental 
speech errors decreases with age (Creaghead, Newman, \& Secord, 1989); therefore, children who continue to demonstrate use of phonological processes after the point at which they typically cease to be used may have deficits in the underlying representation (critical age hypothesis; Bishop \& Adams, 1990).

Additionally, the relation between vocabulary and phonological awareness may be moderated by age, given the extant literature. The neighborhood density model suggests that as a child's age increases, phonological boundaries must become more distinct due to the increasing number of words in the mental lexicon; therefore, as age increases, so too does the specificity of lexical representations (e.g., Logan, 1992; Luce, 1986).

What is lacking in the research is an examination of possible interactions among these variables. That is, research has examined the impact that age has on one set of skills (e.g., speech sound accuracy) but has not examined whether the impact that speech sound accuracy or vocabulary has on phonological awareness is moderated by age. This is a crucial relation to investigate, given the inconsistent findings regarding the relation between speech sound accuracy and phonological awareness (e.g., Catts, 1991; Lewis \& Freebairn, 1992; Bird, Bishop, \& Freeman, 1995; Carroll et al., 2003).

In addition to the need to clarify age's role in the relation between speech sound accuracy and phonological awareness, it is also critical to disentangle the role of age in the relation between SES and phonological awareness. Several studies indicate that SES and phonological awareness are related, but no known studies have examined the possibility that age moderates this relation (i.e., that the effect of SES on phonological awareness is different at different ages). There are at least two potential reasons to explore this possibility, one psychometric and one theoretical/pragmatic. From a psychometric explanation, younger children score lower on measures of phonological awareness. Hence, their scores on the measure are nearer to the floor of the measure and may contain a greater percentage of error than do scores for older children who score higher on the measure. Hence, a difference in predictive variance of phonological awareness measures may be the result of lower reliability.

From a theoretical/pragmatic explanation, phonological awareness could get more predictive with age because the older a child gets, the more likely he or she is to have been exposed to more formal-like instructional or educational activities regarding literacy, either in the home or in preschool. Hence, younger children may have the capacity for a certain level of phonological awareness development, but this is not realized because they have had no or limited exposure to activities that help realize that potential. Older children's demonstrated abilities come closer to their capacities because of more systematic exposure to activities - whatever they may be - that are responsible for the development of phonological awareness. Therefore, young children may display lower phonological awareness because they lack capacity, exposure, or both, whereas in older children, a display of lower phonological awareness skills is more likely to represent capacity, signifying risk for reading problems.

In either case, it would be expected that the relation between SES and measured phonological awareness skills would be weaker for younger children than it is for older children. Whereas there is likely a general trend for SES to be related to phonological awareness, the size of this relation will be smaller in younger children because of weaker psychometric properties of the measures, lack of exposure to activities that promote the development of phonological awareness, or both.

Due to the long-term impact of phonological awareness deficits, it is important to investigate the factors that could potentially contribute to and/or interact with the development of the skill. This study sought to remedy some of the methodological shortcomings found in extant literature (e.g., small sample sizes, measurement issues, clarification regarding impact of age on relations). Specifically, the research questions addressed were as follows: (a) How much unique variance in phonological awareness is explained by vocabulary, speech sound accuracy, SES, and age?; (b) Is the relation between speech sound accuracy and phonological awareness moderated by age?; (c) Is the relation between vocabulary and phonological awareness moderated by age?; and (d) Is the relation between SES and phonological awareness moderated by age?

It was hypothesized that each skill or variable would contribute unique variance to phonological awareness. Additionally, it was hypothesized that age would moderate all relations, given the theoretical underpinnings aforementioned as well as extant literature suggesting that age has an impact on these variables.

\section{$\overline{\text { Method }}$ Participants}

A total of 718 children between the ages of 24 and 72 months were recruited from nine preschool centers in a moderately sized city in North Florida. Eighteen children were not included in the final sample because of missing data. The final sample comprised 92 (13\%) 2-year-olds, 198 (28\%) 3-year-olds, 261 (37\%) 4-year-olds, and 149 (22\%) 5-year-olds. Children from such a wide range of age groups were selected secondary to one of the research questions being asked. Previous research indicates that children, even those as young as 2 years of age, are capable of phonological awareness (e.g., Lonigan et al., 1998). Additionally, to capture the developmental progression of phonological awareness, 
vocabulary, and speech sound accuracies, a wide range of ages was needed.

SES status was determined based on the funding source of the preschool the child attended and was dummy coded as follows: 1 = higher SES, $0=$ lower $S E S$. Children attending a federally funded program (i.e., Head Start) were designated as being from homes of lower SES. Children from lower SES homes comprised $28 \%$ of the sample $(n=195)$, with 87 boys $(45 \%)$ and 108 girls (55\%). This group contained 20 Caucasian children (10.3\%), 169 African American children (86.7\%), and 6 children classified as being from other racial backgrounds (3.1\%). The group comprised $1(0.5 \%)$ twoyear-old, 53 (27\%) three-year-olds, 92 (47\%) four-yearolds, and 49 (25\%) five-year-olds.

Children attending private-pay preschools were designated as being from homes of middle or higher SES. In terms of the children from middle SES homes $(n=505)$, there were 261 males $(52 \%)$ and 244 females (48\%). This group contained 472 Caucasian children (93.5\%), 20 African American children (4\%), and 13 children classified as being from other racial backgrounds (2.6\%). This group comprised 91 (18\%) 2-year-olds, 145 (29\%) 3-year-olds, 169 (34\%) 4-year-olds, and $100(20 \%) 5$-year-olds.

The children were not identified a priori as having any speech, language, or learning needs. The investigators were blind as to whether any speech-language interventions were occurring with the children. All children's hearing was screened by the school nurse within 3 months of the study. There were no exclusion criteria. All children for whom parental consent was obtained participated. Additionally, the child had to be able to complete the assessment, and the examiners ruled out frank visual, auditory, or intellectual problems. Children were placed into a category (i.e., speech impairment, language impairment, speech and language impairment by SES) if they scored $1 S D$ or more below the mean of the speech sound accuracy measures or the vocabulary measures. The purpose of this subgrouping was to investigate if the relations that emerged from analyses differed by speech or language subgroup.

\section{Procedure}

Following informed consent, children were tested individually by trained research assistants in their preschool centers. Test administration for individual children was conducted over two to four sessions within a 2-week period to ensure optimal performance on all tasks. Children completed two standardized tests of vocabulary, eight tests of phonological awareness, and two speech sound accuracy tasks.

Vocabulary measures. The Peabody Picture Vocabulary Test-Revised (PPVT-R; Dunn \& Dunn, 1981) was used to assess receptive vocabulary skills. Expressive vocabulary was assessed with the Expressive One-Word Picture Vocabulary Test-Revised (EOWPVT-R; Gardner, 1990). Both of these measures have demonstrated appropriate reliability (i.e., internal consistency values of .96 and .95 , respectively, with this age group). Both measures report moderate to strong correlations ( $r$ s ranging from .45 to .87) with broader measures of language (e.g., Clinical Evaluation of Language Fundamentals-3; Semel, Wiig, \& Secord, 1995), demonstrating validity of the measures. Additionally, both measures are appropriate for the age range of children who participated in this study, given the nature of their tasks (i.e., pointing to a described picture or naming a pictured object).

Phonological awareness measures. The rationale behind this test design was to guarantee that the full spectrum of children's phonological awareness was assessed, as some measures tapped more than one level of linguistic complexity. The tasks were the precursors to the Test of Preschool Early Literacy (TOPEL; Lonigan, Wagner, Torgesen, \& Rashotte, 2007).

Three primary skills were assessed through eight tasks. The skills were as follows: rhyming, blending, and elision. Rhyming tasks allowed participants to match or judge if words rhymed. Blending tasks allowed the participants to blend parts of a word together to make a whole word (starting with larger chunks, such as blending words into compound words and then moving to phonemes). Finally, elision tasks required the participants to delete parts of a word (again, moving from larger chunks to phonemes).

In the rhyme oddity task, children were presented with three pictured words that were named by the examiner. Children were asked to select the one not rhyming with (or that "did not sound the same as," or was "different than") the other two. The rhyme matching task used the same word list and same pictures as the rhyme oddity task. On this task, children were presented with a picture on a small card and had to indicate with which of two additional pictured words it rhymed. The examiner named all three pictures before and during a trial. In both tasks, the position of the matching word across trials was determined randomly and was the same for all children.

Word blending required children to combine singlesyllable words to form a compound word with the use of picture cards (e.g., "This is a cow, and this is a boy."). Nonpictured blending required children to combine word elements to form a word. Children were presented with a puppet who "has a hard time saying words right - they come out funny." The puppet spoke isolated word elements, and children were asked to "Tell me what word the puppet is trying to say." Multiple levels of linguistic complexity were assessed by this task to guard against confounding linguistic complexity with task demands. 
Items were arranged by order of difficulty, with items assessing lower levels of linguistic complexity administered before items assessing higher levels of linguistic complexity (i.e., moving from blending syllables to blending a singleton onset and a rime unit to blending three to four phonemes into a word). Finally, multiple-choice blending also required children to combine syllables, onsets and rimes, or phonemes to form a word. On this task, however, children were shown three pictures that were labeled by the examiner prior to the puppet's presentation of the auditory stimuli, and children either said or pointed to the picture of the blended word. Order of presentation, in terms of linguistic complexity, was the same as in nonpictured blending.

Word elision required children to delete a singlesyllable word from a compound word. For example, the examiner showed the child two pictures and named them (e.g., "This is a bat, and this is a man."); the examiner asked the child to say the compound (e.g., "Say, 'batman") and then asked the child to say the word with part of it deleted (e.g., "Say 'batman' without saying 'man."'). Nonpictured elision required children to say a word minus a specific sound. A puppet asked children to say a word (e.g., "Say, 'Mike.") and then to say the word with a sound missing (e.g., "Now say 'Mike' without ' $k$.'”). Items were arranged by level of linguistic complexity within the nonpictured elision task. Tasks progressed from deleting a syllable from a word to removing a singleton onset from a word to deleting a single consonant coda from a word. Finally, multiplechoice elision also required children to say a word minus a word element. On this task, children were shown three pictures that were labeled by the examiner prior to the puppet's presentation of the stimuli, and children could say or point to the picture of the elided word. Items were arranged by level of linguistic complexity within the multiple choice elision task in the same progression as in nonpictured elision.

Nondifferential positive feedback was offered on test trials. All correct responses were real words. Several items on the phonological awareness tasks utilized pictures to reduce memory demands. Each of the tasks included at least two practice items that were followed by correction, explanation, and readministration if the child gave an incorrect answer or confirmation and explanation if the child gave the correct answer. If the child missed both practice items, testing ceased and was attempted on a second day. All 10 or 11 test trials within each measure were administered to all children (i.e., no ceiling criterion was used).

Speech sound accuracy measures. Most studies examining the relation between speech sound accuracy and phonological awareness have used either a single-word naming task or a nonword repetition task to assess speech sound accuracy. This study used both types of tasks. The real word measure was the Goldman-Fristoe Test of Articulation (GFTA; Goldman \& Fristoe, 1986). The Sounds-in-Words subtest was administered individually to each child, and the administration was tape recorded. Dialectal differences in productions were scored as errors (e.g., $f$ for th in African American English), and, as Washington and Craig (1992) indicated, there was no need for scoring adjustments for speakers of Black English, meaning that the scoring guidelines for the GFTA-2 do not penalize African American English dialect to a degree that is clinically significant. Level 1 scoring procedures were used (i.e., each sound production was judged for the presence of error but not for the type of error).

Interrater reliability was calculated for a random selection of $10 \%$ ( $n=70)$ of the sample. Two certified speech-language pathologists transcribed each selection independently. After the selections were scored, an item-by-item analysis was conducted. Reliability was calculated in the following way:

\section{no. of agreements/(no. of agreements} + disagreements $) \times 100$,

per Miccio, Elbert, and Forest (1999). Disagreements were resolved by consensus. Interrater reliability was $93 \%$.

In addition, children completed a nonword repetition task. Children listened to a series of nonwords and then were asked to repeat them back to the examiner. The stimuli list began with monosyllabic nonwords and moved to two-syllable, three-syllable, and four-syllable nonwords (e.g., bap, baw, -- doib, noi - gaw - fef, taw -- goi -fo -- chob). There was a ceiling of four consecutive incorrect responses. These were scored online, and all consonants were coded as either correct or incorrect. Speech sound inaccuracies were coded as incorrect productions. Based on the findings of McDowell, Lonigan, and Goldstein (2004) stating that connected speech samples did not predict decoding skills, a conversational sample was not collected. Additionally, Ingram (1994) indicated that articulation tests can provide comparable data in a more time-efficient manner than conversation sampling and transcription.

\section{$\overline{\text { Results }}$ Preliminary Analyses}

Preliminary analyses were conducted to gather descriptive information on the sample and to examine group differences in performance. The data were also disaggregated based on the subgrouping that occurred after initial testing (i.e., speech impairment, language impairment, speech and language impairment, and typically developing by SES group). For the children in the 
higher SES group $(n=505), 4 \%$ fell into the category of speech impairment, $2 \%$ were in the language impairment category, $3 \%$ were in the speech and language impairment category, and $91 \%$ were in the typically developing category. For the children from lower SES homes $(n=195), 9 \%$ fell into the category of speech impairment, $19 \%$ were in the language impairment category, $24 \%$ were in the speech and language impairment category, and $48 \%$ were in the typically developing category. Potential differences between these subgroups were explored with no statistically significant differences obtained. Therefore, the group data were collapsed and analyzed together.

Descriptive statistics for age and the measures of phonological awareness, vocabulary, and speech sound accuracy for children by age and SES group are shown in Table 1. Scores represent raw scores. Nonword repetition had 20 possible points. The GFTA data represent number of correct consonants produced (all consonants were scored - not just the target sound-for a total of 82 possible points). The vocabulary measure scores that are reported are standard scores $(M=100, S D=15)$. Table 1 illustrates that scores on all measures are increasing with age and that children from lower SES homes generally performed worse than children from higher SES homes, with the exception of the speech measures.

All variables were transformed to $z$ scores. Possible floor effects were noted in the 2- and 3-year-olds from homes of higher SES and in the 2-, 3-, and 4-year-olds from homes of lower SES on tasks of nonpictured elision and elision word. Additional floor effects on nonpictured blending were noted in the 2-year-olds from homes of higher SES. Possible ceiling effects were noted in rhyme matching and multiple choice blending in 5-year-olds from homes of higher SES and in multiple choice blending in 5-year-olds from homes of lower SES. Detected outliers were replaced, and violations of normality were detected, but the analyses of the transformed variables lead to the same conclusions. Therefore, all analyses were carried out using untransformed variables.

After examining for violations of normality, the reliability of the measures used within the study was calculated. The tasks involving elision, blending, and rhyme yielded internal consistency values of .71, .68, and .62 , respectively. When corrected for attenuation using Spearman-Brown correction, the coefficients increased to $.77, .72$, and .70 , respectively.

Examination of the relations among the multiple measures was conducted to assess for practicality and reasonability of the formation of composite variables. Bivariate correlations among the measures are shown in Table 2 . The vocabulary measures correlated highly with each other $(r=.85)$. The two speech sound accuracy measures correlated moderately with each other $(r=.54)$. Because of these correlations and because of conceptual appropriateness, the two vocabulary measures were used to create a vocabulary composite variable. Likewise, the two speech sound accuracy variables were used to create a speech sound accuracy composite variable.

Several intercorrelations among the phonological awareness variables were evident. The eight phonological awareness tasks were submitted to a principal component analysis with direct Oblimin rotation and Kaiser normalization. A one-component solution emerged, with the loadings of the eight variables on the one component ranging from .43 to .87. Thus, a composite variable of all eight phonological awareness measures was computed.

Finally, bivariate correlations among the composite variables were conducted (see Table 3 ) with statistically significant relations emerging.

\section{Predicting Phonological Awareness}

To answer the first question regarding the amount of variance in phonological awareness explained by speech sound accuracy, vocabulary, SES, and age, multiple regression analysis was used. The use of multiple independent variables provides statistical control in the estimation of the unique effect of each independent variable on the outcome, which is critical when independent variables are correlated with one another (Cohen \& Cohen, 1975).

A series of regression analyses examined the extent to which individual differences on the independent variables explained subsequent individual differences in phonological awareness (see Table 4). The regression model (Model 1) examined the simultaneous influence of all of the composite variables. The model was statistically significant, $F(4,675)=367.72, p=.001$, and accounted for $69 \%$ of the variance in phonological awareness. All of the included variables contributed significant amounts of unique variance to the model. The direction of the relationships is positive (i.e., as age, SES, vocabulary, and speech sound accuracy increase, phonological awareness increases).

\section{Age as a Moderator}

To address the remaining research questions, hierarchical multiple regression analyses were performed to further investigate the relations among the variables and to test the prediction that age moderates the relations among speech sound accuracy and phonological awareness, between vocabulary and phonological awareness, and between SES and phonological awareness (i.e., to determine if the addition of information regarding age and then addition of the predictor variables improved prediction of phonological awareness beyond that afforded by differences in predictor variables alone). An advantage to the hierarchical multiple regression analysis of data is that once the order of the independent 
Table 1. Means and standard deviations for chronological age and indices of vocabulary, phonological awareness, and speech sound accuracy for children, by age and socioeconomic status (SES).

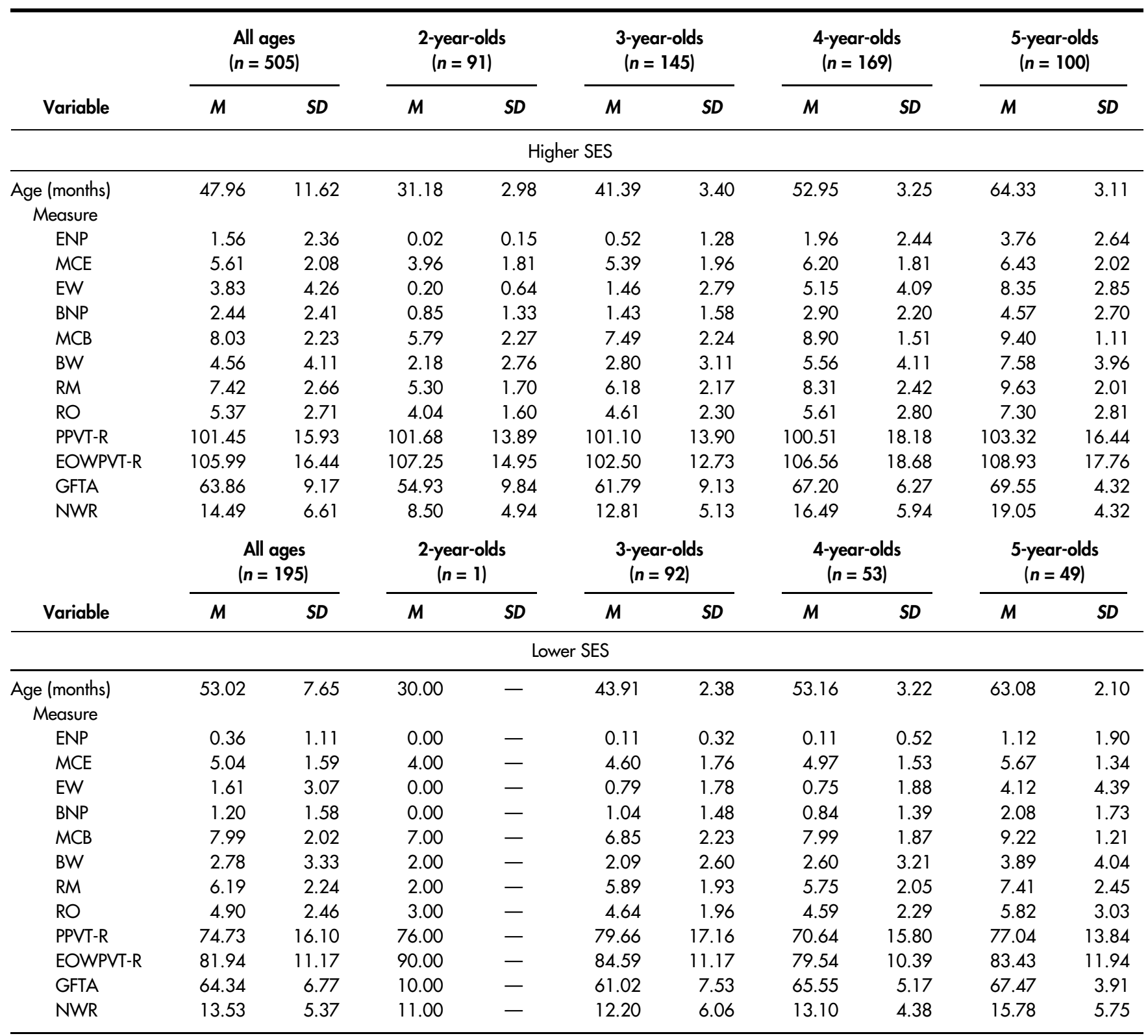

Note. Em dashes indicate that only 1 child was in this group; thus, there is no SD. ENP = Elision Nonpicture; MCE = Multiple Choice Elision; EW = Elision Word; BNP = Blending Nonpicture; MCB = Multiple Choice Blending; BW = Blending Word; RM = Rhyme Matching; RO = Rhyme Oddity; PPVT-R = Peabody Picture Vocabulary Test-Revised; EOWPVT-R = Expressive One-Word Picture Vocabulary Test-Revised; GFTA = Goldman-Fristoe Test of Articulation; NWR = Nonword Repetition.

variables has been specified, a unique partitioning of the total $Y$ variance accounted for by the independent variables may be made.

To determine whether age moderated the relations among speech sound accuracy, vocabulary, and phonological awareness, examination of the effects of interaction terms on the significance of the model occurred. Interaction terms involving age were created and entered into the model as a second block (see Table 4, Model 2).
The overall model significantly accounted for a substantial amount of the variance in phonological awareness (i.e., $70 \%), F(7,672)=226.47, p=.001$. In this model, age, vocabulary, speech sound accuracy, and the Age $\times$ Speech Sound Accuracy and Age $\times$ SES interactions were significant and accounted for an additional $1 \%, 1 \%, 1 \%, 2 \%$, and $1 \%$, respectively, of the unique variance in phonological awareness after all variables were already in the model. The Age $\times$ Vocabulary interaction 
Table 2. Bivariate correlations among variables $(N=700)$.

\begin{tabular}{|c|c|c|c|c|c|c|c|c|c|c|c|c|}
\hline 1. ENP & - & & & & & & & & & & & \\
\hline 2. MCE & $.23^{* * *}$ & - & & & & & & & & & & \\
\hline 3. EW & $.71^{* * *}$ & $.36^{* * *}$ & - & & & & & & & & & \\
\hline 4. BNP & $.68^{* * *}$ & $.28^{* * *}$ & $.59^{* * *}$ & - & & & & & & & & \\
\hline 5. $M C B$ & $.43^{* * *}$ & $.39^{* * *}$ & $.51^{* * *}$ & $.43^{* * *}$ & - & & & & & & & \\
\hline 8. RO & $.46^{* * *}$ & $.25^{* * *}$ & $.52^{* * *}$ & $.40^{* * *}$ & $.30^{* * *}$ & $.45^{* * *}$ & $.53^{* * *}$ & - & & & & \\
\hline 9. PPVT-R & $.58^{* * *}$ & $.36^{* * *}$ & $.69^{* * *}$ & $.58^{* * *}$ & $.58^{* * *}$ & $.58^{* * *}$ & $.62^{* * *}$ & $.47^{* * *}$ & - & & & \\
\hline 10. EOWPVT-R & $.62^{* * *}$ & $.38^{* * *}$ & $.72^{* * *}$ & $.58^{* * *}$ & $.55^{* * *}$ & $.56^{* * *}$ & $.63^{* * *}$ & $.51^{* * *}$ & $.84^{* * *}$ & - & & \\
\hline 11. GFTA & $.41^{* * *}$ & $.35^{* * *}$ & $.49^{* * *}$ & $.43^{* * *}$ & $.46^{* * *}$ & $.39^{* * *}$ & $.45^{* * *}$ & $.31^{* * *}$ & $.55^{* * *}$ & $.54^{* * *}$ & - & \\
\hline 12. NWR & $.48^{* * *}$ & $.29^{* * *}$ & $.56^{* * *}$ & $.48^{* * *}$ & $.41^{* * *}$ & $.42^{* * *}$ & $.49^{* * *}$ & $.43^{* * *}$ & $.55^{* * *}$ & $.56^{* * *}$ & $.58^{* * *}$ & - \\
\hline
\end{tabular}

${ }^{* * *} p<.001$.

was not significant, indicating that it did not contribute additional unique variance to the model above and beyond that accounted for by the other variables.

Because the test of the interaction was significant, the effect of speech sound accuracy on phonological awareness is then described as a function of age (see Figure 1). The effect of speech sound accuracy on phonological awareness is amplified as age increases. Increases in speech sound accuracy led to greater changes in phonological awareness as age increased. Second, because the test of the SES $\times$ Age interaction was significant, the effect of SES on phonological awareness is also then described as a function of age (see Figure 2). The effect of SES on phonological awareness is amplified as age increases (given the positive beta). That is, increases in SES led to greater changes in phonological awareness as age increased.

\section{$\overline{\text { Discussion }}$}

The first goal of this study was to determine the nature of the relations among the variables commonly associated with reading success by answering the following

Table 3. Bivariate correlations among composite variables $(N=700)$.

\begin{tabular}{lcccc}
\hline Variable & $\mathbf{1}$ & $\mathbf{2}$ & $\mathbf{3}$ & $\mathbf{4}$ \\
\hline 1. SSA & - & & & \\
2. PA & $.65^{* * *}$ & - & & \\
3. Vocab & $.63^{* * *}$ & $.80^{* * *}$ & - & \\
4. Age & $.62^{* * *}$ & $.75^{* * *}$ & $.78^{* * *}$ & - \\
\hline
\end{tabular}

Note. SSA = Speech Sound Accuracy composite; PA = Phonological Awareness composite; Vocab $=$ Vocabulary composite.

${ }^{* * *} p<.001$. question: How much unique variance in phonological awareness is explained by vocabulary, speech sound accuracy, SES, and age? It was hypothesized that each skill or variable would account for unique variance in phonological awareness. This hypothesis was supported by the data. Each skill or variable predicted unique variance in phonological awareness. Overall, the results provide support for the phonological distinctness hypothesis and the lexical restructuring model. Speech sound accuracy predicted unique variance in phonological awareness, even after holding vocabulary constant. Additionally, vocabulary predicted unique variance in phonological awareness, even after accounting for variance common to speech sound accuracy.

Table 4. Predicting Phonological Awareness from interaction terms $(N=700)$.

\begin{tabular}{lcccc}
\hline Predictor variable & $\boldsymbol{R}$ & $\Delta \boldsymbol{R}^{2}$ & $\boldsymbol{\beta}$ & $\boldsymbol{F}$ ratio \\
\hline Model 1 & .83 & .69 & & $367.72^{* * * a}$ \\
$\quad$ Vocabulary & & .20 & .49 & $13.10^{* * *}$ \\
SSA & .05 & .17 & $5.89^{* * *}$ \\
SES & .04 & .14 & $4.98^{* * *}$ \\
Age & .07 & .26 & $7.21^{* * *}$ \\
Model 2 & .70 & & $226.47^{* * * b}$ \\
Vocabulary & .01 & .32 & $2.58^{* *}$ \\
SSA & .01 & .28 & $2.34^{*}$ \\
SES & .00 & .20 & 1.39 \\
Age & .01 & .15 & $2.40^{*}$ \\
Age $\times$ Vocabulary & .00 & .14 & 1.12 \\
Age $\times$ SSA & .02 & .47 & $3.94^{* * *}$ \\
Age $\times$ SES & .01 & .32 & $2.33^{*}$ \\
\hline Note. SES $=$ socioeconomic status. & & & \\
${ }^{a} d f s=5,674 .{ }^{b} d f s=9,670$. & & & \\
${ }^{*} p<.05 .{ }^{* *} p<.01 .{ }^{* * *} p<.001$. & & & \\
\hline
\end{tabular}


Figure 1. Relations between Speech Sound Accuracy (SSA) and Phonological Awareness (PA), moderated by age (in years).

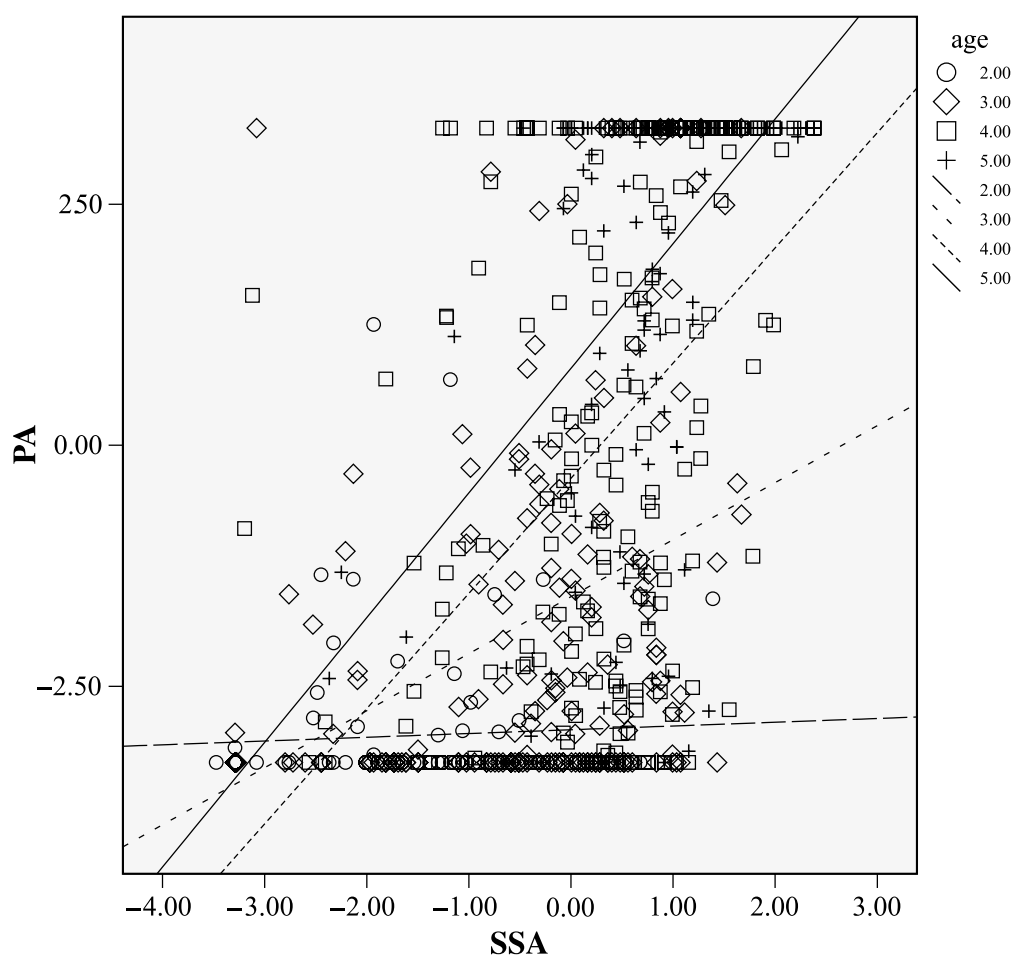

Figure 2. Relations between age (in months) and Phonological Awareness (PA), moderated by socioeconomic status (SES).

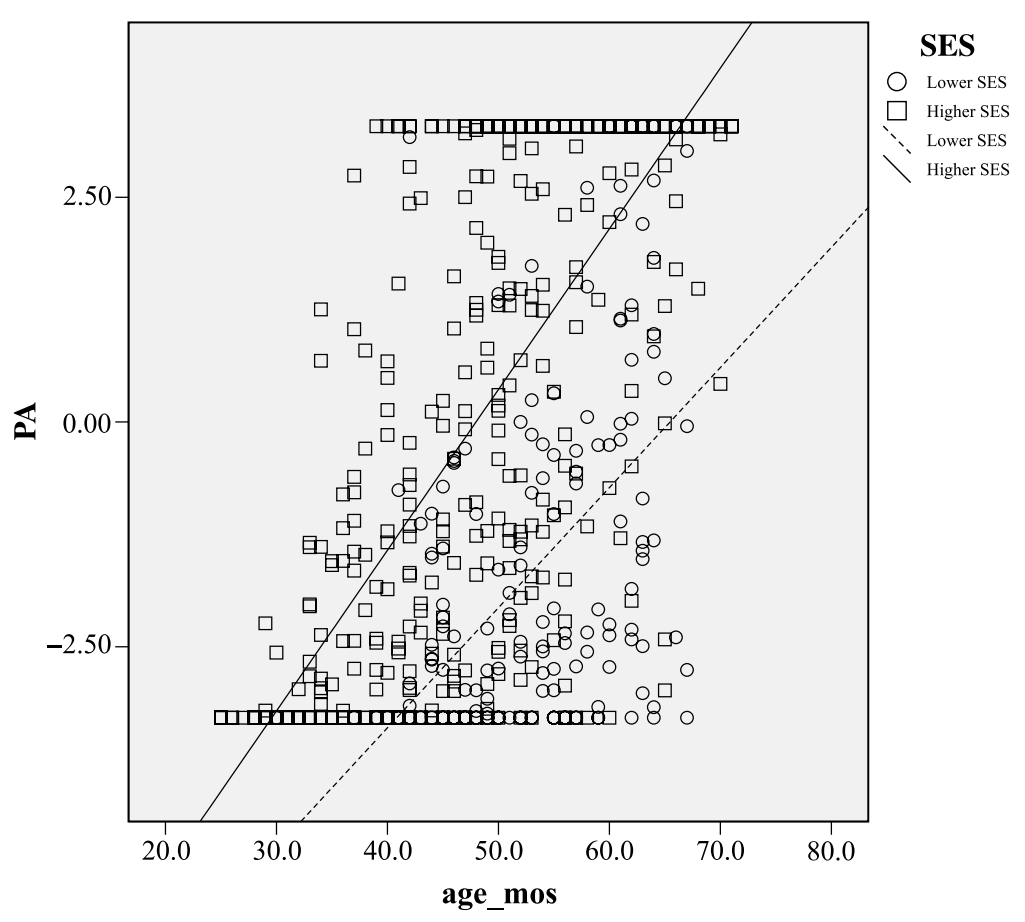




\section{Main Effects of Speech Sound Accuracy and Vocabulary}

In this study, speech sound accuracy skills contributed unique variance to the prediction of phonological awareness, even when holding the other variables constant. These results support the prediction stemming from the phonological distinctness hypothesis, which indicates that deficits in phonological awareness could be directly attributed to deficits in the child's underlying phonological system. In this study, deficits in speech sound accuracy (a gross measure of a child's productive phonological system) predicted deficits in phonological awareness.

In addition to speech sound accuracy skills, vocabulary skills contributed unique variance to the prediction of phonological awareness, even when holding the other variables constant. These results lend support to the lexical restructuring model in that deficits in phonological awareness could be directly attributed to deficits in the lexicon (due to poor or insufficient restructuring). In this study, deficits in vocabulary were predictive of deficits in phonological awareness.

These results also offer support to the notion that the lexical restructuring model and the phonological distinctness hypothesis may not be two distinct theories but, perhaps, interwoven. According to the lexical restructuring model, the phonological domains (i.e., phonological awareness and speech sound accuracy) should be related through the lexicon. This was the case. The phonological distinctness hypothesis predicts that speech accuracy should predict phonological awareness when vocabulary is controlled. This was also the case. Findings from this study indicate that these two hypotheses may be complimentary rather than contrasting, with both accounting for variables that predict phonological awareness.

\section{Main Effects of SES and Age}

Consistent with prior studies, SES differences were found on most of the measures of phonological awareness and language (Bird et al., 1995; Lonigan et al., 1998). Children from higher SES backgrounds outperformed children from lower SES backgrounds. The exceptions included rhyme oddity within the 3 -year-old group and GFTA scores for the total group. These findings were consistent with results of other studies indicating that children from homes of lower SES perform more poorly on measures of phonological awareness (e.g., Bowey, 1995; Lonigan et al., 1998) and vocabulary (e.g., Hart \& Risley, 1995).

Results of this study were also consistent with existing literature indicating that age predicts performance on phonological awareness tasks (e.g., Foy \& Mann, 2001; Lonigan et al., 1998; Wagner, Torgesen, Laughon, Simmons, \& Rashotte, 1993).

\section{Age as a Moderator}

Age and speech sound accuracy. These results expand on these findings by demonstrating that age moderates the relations among speech sound accuracy and phonological awareness. As children get older, the continued presence of inaccuracies in the production of words more strongly predicts poorer performance on tasks involving phonological awareness. This was an important question to address, as some investigators have concluded that speech sound accuracy is not related to reading but have included older children (e.g., Bishop \& Adams, 1990; Lewis \& Freebairn, 1992). Results from the current study indicate that for older preschool children, poor speech sound accuracy skills are related to poorer phonological awareness skills.

Age and SES. The most interesting finding regarding SES is the role that age seems to play in moderating the relations between SES and phonological awareness. In this study, the effect of SES on phonological awareness was a function of age, indicating that as SES increased, greater changes in phonological awareness were amplified by age. Extant literature indicates that SES and age (or phonological awareness at different ages) are predictors of later phonological awareness. The effect of SES on phonological awareness is amplified by age so that as children get older, those from homes of higher SES make greater changes in phonological awareness than children from homes of lower SES.

When interpreting the relation between SES and phonological awareness as moderated by age, it becomes critical to consider why age would have a stronger relationship with phonological awareness for children from homes of higher SES. This comes from the aforementioned theoretical/pragmatic consideration. Children from homes of higher SES are more likely to have had exposure to activities that help them realize their potential; therefore, displays of lower phonological awareness most likely represent lower capacity. In contrast, children from homes of lower SES may not have had exposure to such reading-related activities, so poor performance on phonological awareness tasks simply may be the result of unrealized potential. This leads to the implication of support for early intervention, highquality preschool experiences, and family education regarding at-home literacy experiences.

Age and vocabulary. Another finding that emerged from the current study was that effect of vocabulary on phonological awareness was not a function of age. One plausible explanation for this lack of moderation could be attributed to excessive error variance among the vocabulary and speech sound accuracy measures across age groups. The range for raw scores on the PPVT-R was 3.0 to 103.0. For the EOWPVT-R, raw scores ranged from 3.0 to 77.0. With such large amounts of variation across 
participants, regardless of age, it is unlikely that age would be identified as a significant moderator.

Given the prediction of the lexical restructuring model (i.e., as children get older, their lexicons become more segmentally represented, leading to improvements in phonological awareness), the results of this study do not support this prediction. One likely explanation could be the receptive vocabulary measure used and the potential for cultural bias (e.g., Washington $\&$ Craig, 1992). Differences based on age that would normally be captured by the vocabulary measures may be more accounted for by SES, leaving little leftover variance to be accounted for by age. This could also account for potential problems with the subgrouping of children (e.g., language impairment, language and speech impairment by SES), as the groupings were defined by scores from these potentially biased vocabulary measures.

\section{Limitations and Future Research}

There are a few limitations to this study. The Goldman Fristoe Test of Articulation (Goldman \& Fristoe, 1986) is a single-word naming test that assesses only specific phonemes within words. Although this type of test provides information about word-level intelligibility, expressive phonology may be better assessed by other means (instead of with a single-word naming task). One such way is through determining Percent of Consonants Correct-Revised (PCC-R; Shriberg, Austin, Lewis, McSweeny, \& Wilson, 1997), which is a count of consonantal errors. PCC-R analyses appear to be more sensitive to changes within a child's phonological system than a single-word naming task (Ingram, 2000). One other possible limitation to this study is that no distinction was made between motor-based and phonologically based speech sound accuracy deficits. Additionally, extant literature indicates that severity of speech sound accuracy deficits may play a critical role in the prediction of reading-related difficulties (e.g., Bird et al., 1995; Nathan et al., 2004). Our data were pooled together after results of a Fisher's $r$ to $z$ transformation indicated no significant differences in the patterns of relations among the variables for children with potential speech sound accuracy and/or language impairments. However, the data were not examined in terms of severity.

Another limitation of this study is that we neither measured nor controlled for children's emergent literacy experiences in the preschool centers. Although we know that the children in our sample had exposure to books at school, we cannot be precise about the amount or type of exposure. Research has shown that preschool experiences enhance oral language skills (e.g., Burgess, 2002; Dickinson, McCabe, Anastasopoulos, PeisnerFeinberg, \& Poe, 2003; Storch \& Whitehurst, 2002).
Given that this study indicated that both speech sound accuracy and vocabulary made independent contributions to the prediction of phonological awareness, another clinically useful study would be to examine the error patterns that emerge from expressive vocabulary measures. Instead of coding the response as correct or incorrect (as was done in this study), examination of the types of errors made (e.g., whether phonologically similar or semantically similar) may yield interesting, useful information in further defining the role that speech sound accuracy and vocabulary play in the prediction of phonological awareness.

\section{$\overline{\text { Conclusion }}$}

In summary, results from this study provide some support for and add to existing literature regarding the relations among speech sound accuracy, vocabulary, age, SES, and phonological awareness. The findings from the current study lend support to the distinctness hypothesis as well as the lexical restructuring model in that speech sound accuracy and vocabulary both accounted for unique variance in phonological awareness after holding the other constant. Additionally, results from this study indicate that age moderates the relation between speech sound accuracy and phonological awareness (i.e., as speech sound accuracy increases, changes in phonological awareness are amplified by increases in age). Another novel finding from this study is that age moderates the relation between SES and phonological awareness (i.e., as SES increases, changes in phonological awareness are amplified with increases in age). This study did not find an interaction between vocabulary, age, and phonological awareness.

\section{Acknowledgments}

Preparation of this work was supported, in part, by Grants HD38880, HD36067, HD36509, and HD30988 awarded to Christopher J. Lonigan from the National Institute of Child Health and Human Development, Grant 90YF0023 from the Administration for Children and Families, and Grant REC-0128970 from the National Science Foundation. Views expressed herein are the authors' and have not been cleared by the grantors.

\section{References}

Adams, M. (1990). Beginning to read: Thinking and learning about print. Cambridge, MA: The MIT Press.

Allington, R. (1984). Content, coverage, and contextual reading in reading groups. Journal of Reading Behavior, 16, 85-96.

Baydar, N., Brooks-Gunn, J., \& Furstenberg, F. (1993). Early warning signs of functional illiteracy: Predictors in childhood and adolescence. Child Development, 64, 815-829. 
Bird, J., Bishop, D., \& Freeman, N. (1995). Phonological awareness and literacy development in children with expressive phonological impairments. Journal of Speech and Hearing Research, 38, 446-462.

Bishop, D. V. M., \& Adams, C. (1990). A prospective study of the relationship between specific language impairment, phonological disorders, and reading retardation. Journal of Child Psychology and Psychiatry and Allied Disciplines, 31, 1027-1050.

Blachman, B. (1991). Early intervention for children's reading problems: Clinical applications of the research in phonological awareness. Topics in Language Disorders, 12 , 51-65.

Bowey, J. (1995). Socioeconomic status differences in preschool phonological awareness and first-grade reading achievement. Journal of Educational Psychology, 87, 476-487.

Brown, A., Palinscar, A., \& Purcell, L. (1986). Poor teachers: Teach, don't label. In U. Neisser (Ed.), The school achievement of minority children: New perspectives ( pp. 105-143). Hillsdale, NJ: Erlbaum.

Burgess, S. (2002). Shared reading correlates of early reading skills [Electronic journal article]. Reading Online, 5, Retrieved June 20, 2007, from http://www.readingonline .org/articles/burgess/index.html

Burt, L., Holm, A., \& Dodd, B. (1999). Phonological awareness skills of 4-year-old British children: An assessment and developmental data. International Journal of Language and Communication Disorders, 34, 311-335.

Carroll, J. M., Snowling, M. J., Hulme, C., \& Stevenson, J. (2003). The development of phonological awareness in preschool children. Developmental Psychology, 39, 913-923.

Catts, H. W. (1991). Early identification of dyslexia: Evidence from a follow-up study of speech-language impaired children. Annals of Dyslexia, 41, 163-177.

Catts, H., \& Kamhi, H. (Eds.). (1999). Language and reading disabilities. Needham Heights, MA: Allyn \& Bacon.

Cohen, J., \& Cohen, P. (1975). Applied multiple regression/ correlation analysis for the behavioral sciences. Hillsdale, NJ: Erlbaum.

Cormier, P., \& Dea, S. (1997). Distinctive patterns of relationship of phonological awareness and working memory with reading development. Reading and Writing: An Interdisciplinary Journal, 9, 193-206.

Creaghead, N. A., Newman, P. W., \& Secord, W. A. (1989). Assessment and remediation of articulatory and phonological disorders. Columbus, $\mathrm{OH}$ : Merrill.

Cunningham, A., \& Stanovich, K. (1998). What reading does for the mind. American Educator, 22, 8-15.

Dickinson, D. K., McCabe, A., Anastasopoulos, L., Peisner-Feinberg, E. S., \& Poe, M. D. (2003). The comprehensive language approach to early literacy: The interrelationships among vocabulary, phonological awareness, and print knowledge among preschool-aged children. Journal of Educational Psychology, 95, 465-481.

Donahue, P., Voelld, K., Campbell, J., \& Mazzeo, J. (1998). National Assessment of Educational Progress 1998 reading report card for the nation and states. Washington, DC: U.S. Government Printing Office.

Dunn, L., \& Dunn, L. (1981). Peabody Picture Vocabulary Test-Revised. Circle Pines, MN: American Guidance Service.
Elbro, C. (1996). Early linguistic abilities and reading development: A review and a hypothesis. Reading and Writing: An Interdisciplinary Journal, 8, 453-485.

Elbro, C., Borstrom, I., \& Petersen, D. K. (1998). Predicting dyslexia from kindergarten: Importance of distinctness of phonological representations of lexical items. Reading Research Quarterly, 33, 36-60.

Elbro, C., Nielsen, I., \& Petersen, D. K. (1994). Dyslexia in adults: Evidence from deficits in nonword reading and in the phonological representation of lexical items. Annals of Dyslexia, 44, 205-226.

Fowler, A. E. (1991). How early phonological development might set the stage for phonological awareness. In S. Brady \& D. Shankweiler (Eds.), Phonological processes in literacy: A tribute to Isabelle Y. Liberman (pp. 97-117). Hillsdale, NJ: Erlbaum.

Fowler, A. E., \& Swainson, B. (2004). Relationships of naming skills to reading, memory, and receptive vocabulary: Evidence for imprecise phonological representations of words by poor readers. Annals of Dyslexia, 54, 247-280.

Foy, J. G., \& Mann, V. (2001). Does strength of phonological representations predict phonological awareness in preschool children? Applied Psycholinguistics, 22, 301-325.

Gardner, M. F. (1990). Expressive One-Word Picture Vocabulary Test-Revised. Novato, CA: Academic Therapy Publications.

Garlock, V. M., Walley, A. C., \& Metsala, J. L. (2001). Ageof-acquisition, word frequency, and neighborhood density effects on spoken word recognition: Implications for early reading ability. Journal of Memory and Language, 44, 1-25.

Goldman, R., \& Fristoe, M. (1986). Test of Articulation. Circle Pines, MN: American Guidance Service.

Hart, B., \& Risley, T. R. (1995). Meaningful differences in the everyday experiences of young American children. Baltimore: Paul H. Brookes.

Hecht, S. A., \& Greenfield, D. B. (2002). Explaining the predictive accuracy of teacher judgments of their students' reading achievement: The role of gender, classroom behavior, and emergent literacy skills in a longitudinal sample of children exposed to poverty. Reading and Writing, 15, 789-809.

Ingram, D. (1994). Articulation testing versus conversational speech sampling: A response to Morrison and Shriberg (1992). Journal of Speech and Hearing Research, 37, 935-936.

Ingram, D. (2000, June). The measurement of whole word productions. Paper presented to the Child Phonology Conference, University of Northern Iowa, Cedar Falls.

Juel, C. (1988). Learning to read and write: A longitudinal study of 54 children from first through fourth grades. Journal of Educational Psychology, 80, 437-447.

Larrivee, L. S., \& Catts, H. W. (1999). Early reading achievement in children with expressive phonological disorders. American Journal of Speech-Language Pathology, 8, 118-128.

Lewis, B. A., \& Freebairn, L. (1992). Residual effects of preschool phonology disorders in grade school, adolescence, and adulthood. Journal of Speech and Hearing Research, 35, 819-831.

Logan, J. S. (1992). A computational analysis of young children's lexicons (Research on Spoken Language Processing Technical Report No. 8). Bloomington, IN: Indiana University Speech Research Laboratory. 
Lonigan, C. J. (2003). Development and promotion of emergent literacy skills in preschool children at-risk of reading difficulties. In B. Foorman (Ed.), Preventing and remediating reading difficulties: Bringing science to scale (pp. 23-50). Timonium, MD: York Press.

Lonigan, C. J., Burgess, S., Anthony, J., \& Barker, T. (1998). Development of phonological sensitivity in 2- to 5-year old children. Journal of Educational Psychology, 90, 294-311.

Lonigan, C. J., Wagner, R., Torgesen, J. K., \& Rashotte, C. (2007). Test of Preschool Early Literacy. Austin, TX: ProEd.

Luce, P. A. (1986). Neighbourhoods of words in the mental lexicon (Research on Speech Perception Technical Report No. 6). Bloomington, IN: Indiana University Speech Research Laboratory.

Luce, P. A., \& Pisoni, D. B. (1998). Recognizing spoken words: The neighbourhood activation model. Ear and Hearing, 19, 1-36.

McDowell, K. D., Lonigan, C. J., \& Goldstein, H. (2002, November). In Phonological sensitivity and phonological accuracy. Annual meeting of the American SpeechLanguage-Hearing Association, Atlanta, GA

McDowell, K. D., Lonigan, C. J., \& Goldstein, H. (2004, November). Examining relations among expressive phonology, phonological processing, and decoding skills in children. Annual meeting of the American Speech-Language-Hearing Association, Philadelphia, PA.

Metsala, J. (1997). An examination of word frequency and neighborhood density in the development of spoken-word recognition. Memory \& Cognition, 25, 47-56.

Metsala, J. L. (1999). Young children's phonological awareness and nonword repetition as a function of vocabulary development. Journal of Educational Psychology, 91, 3-19.

Metsala, J., \& Walley, A. (1998). Spoken vocabulary growth and segmental restructuring of lexical representations: Precursors to phonemic awareness and early reading ability. In J. Metsala \& L. Ehri (Eds.), Word recognition in beginning reading (pp. 89-120). Mahwah, NJ: Erlbaum.

Miccio, A. W., Elbert, M., \& Forest, K. (1999). The relationship between stimulability and phonological acquisition in children with normally developing and disordered phonologies. American Journal of Speech-Language Pathology, 8, 347-363.

Nathan, L., Stackhouse, J., Goulandris, N., \& Snowling, M. J. (2004). The development of early literacy skills among children with speech difficulties: A test of the critical age hypothesis. Journal of Speech, Language, and Hearing Research, 47, 377-391.

National Assessment of Educational Progress (NAEP). (2005). The NAEP 2005 technical report. Washington, DC: National Center for Educational Statistics.

Oka, E., \& Paris, S. (1986). Patterns of motivation and reading skills in underachieving children. In S. Ceci (Ed.), Handbook of cognitive, social, and neuropsychological aspects of learning disabilities (pp. 115-146). Hillsdale, NJ: Erlbaum.

Rvachew, S., Ohberb, A., Grawburg, M., \& Heyding, J. (2003). Phonological awareness and phonemic perception in 4-year old children with delayed expressive phonology skills. American Journal of Speech-Language Pathology, 12, 463-471.
Semel, E., Wiig, E., \& Secord, W. (1995). Clinical Evaluation of Language Fundamentals-3. San Antonio, TX: The Psychological Corporation.

Shankweiler, D., Crain, S., Brady, S., \& Macaruso, P. (1992). Identifying the causes of reading disability. In P. Gough, L. Ehri, \& R. Treiman (Eds.), Reading acquisition (pp. 275-306). Hillsdale, NJ: Erlbaum.

Shonkoff, J. P., \& Phillips, D. A. (Eds.). (2000). From neurons to neighborhoods: The science of early childhood development. Washington, DC: National Academy Press.

Shriberg, L. D., Austin, D., Lewis, B. A., McSweeny, J. L., \& Wilson, D. L. (1997). The percentage of consonants correct (PCC) matrix: Extensions and reliability data. Journal of Speech, Language, and Hearing Research, 40, 708-722.

Stanovich, K. E. (1986). Matthew effects in reading: Some consequences of individual differences in the acquisition of literacy. Reading Research Quarterly, 21, 360-407.

Storch, S. A., \& Whitehurst, G. J. (2002). Oral language and code-related precursors to reading: Evidence from a longitudinal structural model. Developmental Psychology, 38, 934-947.

Storkel, H. L. (2002). Restructuring of similarity neighbourhoods in the developing mental lexicon. Journal of Child Language, 29, 251-274.

Storkel, H. L., \& Morrisette, M. L. (2002). The lexicon and phonology: Interactions in language acquisition. Language, Speech, and Hearing Services in Schools, 33, 24-37.

Swan, D., \& Goswami, U. (1997). Phonological awareness deficits in developmental dyslexia and the phonological representations hypothesis. Journal of Experimental Child Psychology, 66, 18-41.

Torgesen, J., Wagner, R., Rashotte, C., Alexander, A., \& Conway, T. (1997). Preventive and remedial interventions for children with severe reading disabilities. Learning Disabilities: An Interdisciplinary Journal, 8, 51-62.

Wagner, R. K., Torgesen, J. K., Laughon, P., Simmons, K., \& Rashotte, C. (1993). Development of young readers' phonological processing abilities. Journal of Educational Psychology, 85, 83-103.

Walley, A. C., \& Flege, J. E. (1999). Effects of lexical status on the perception of native and nonnative vowels: A developmental study. Journal of Phonetics, 27, 307-332.

Washington, J. A., \& Craig, H. K. (1992). Articulation test performances of low-income African American preschoolers with communication impairments. Language, Speech, and Hearing Services in Schools, 23, 203-207.

Received December 21, 2004

Revision received July 26, 2005

Accepted December 8, 2006

DOI: $10.1044 / 1092-4388(2007 / 075)$

Contact author: Kimberly D. McDowell, Department of Curriculum and Instruction, Wichita State University, Wichita, KS 67260-0028. E-mail: kim.mcdowell@wichita.edu. 
Copyright of Journal of Speech, Language \& Hearing Research is the property of American Speech-Language-Hearing Association and its content may not be copied or emailed to multiple sites or posted to a listserv without the copyright holder's express written permission. However, users may print, download, or email articles for individual use. 